\section{Aill Aुouress}

ox

\section{E P R O S Y,}

WITH AN ACCOUNT OF A OASE,

Delivered before the Section of Medioine in the Royal Academy of Medicine in Ireland on May 21st, 1915,

By C. M. O'BRIEN, M.D.DuRH., L.R.C.P.IreL.,

PHYSICIAN TO, AND LECTURER IN DERMATOLOGY AT, THE CITY HOSPITAL FOR DISEASHS OF THE SKIN AND CANCER, DUBLIN ; HONORARY MEMBER OF THE DERMATOLOGICAL SOCIETY, FRANCE.

The Literature of Leprosy.

Mr. President and Gentlemen,-In the struggle between man and disease from the dawn of regular history to the present there is no malady which has quickened popular sentiment, taxed human endurance, or aroused universal sympathy to the extent that leprosy has done. In the whole domain of medicine, through every stage of its evolution, there is no single disease which has engaged so many master-minds of every nationality-poet, painter, physician, and divine. Yet the Bible, which is the beginning of wisdom as well as of truth and the foundation of most of the knowledge we possess, has added very little, if anything, of scientific value to the literature of leprosy. It reminds us how our Lord, the greatest physician of all times, being moved to pity at the sight of the lepers, performed one of his greatest miracles on their behalf. Leprosy, once the most generally diffused, and still perhaps the most surely fatal of all maladies, was first obserred in Egypt 1500 B.C. It raged in Italy during the time of Pompey, and subsequently extended from the Equator to the Poles. It was amidst the stir and movement of the Crusades that leprosy became epidemic in western Europe. From the end of the eleventh century for a period of 200 years whole tribes, wandering to and from the East, were exposed to privation and want consequent on unceasing warfare, while many who were not actually so engaged were deprived of the necessaries of life, their lands laid waste by the armies of the Crusaders, and in many instances remaining untilled for want of labourers. Thus, with repeated wars, the imperfect state of agriculture in Europe subjected the inhabitants to constant scarcity of food, want of cleanliness, mendicant misery, the too constant attendants of scurvy, scabies, and psoriasis, with which leprosy was erroneously classed.

No recent or even modern writer has described the symptoms of what we now call leprosy with greater precision than some of the Greek writers. Hippocrates seemed to have known it only by hearsay, and probably confused it with psoriasis; while Aristotle described it more fully. Aretæus in the first century described the same malady under the name elephantiasis, because of some supposed resemblance of the diseased skin to that of the elephant, "for it is disgusting to the sight," says Aretrus, "and in all respects terrible, like the beast of similar name."

The description of leprosy by Aretæus in those far-off days corresponds so completely with the symptoms we now know in more modern times that I am induced to give it in detail, thus: No. 4801.
"Shining tubercles of different size, dusky red or livid in colour, on face, ears, and extremities, together with a thickened and rugous state of the skin, a diminution or total loss of its sensibility, and a falling off of all the hair except that of the scalp. The disease is described as very slow in its progress, sometimes continuing for several years without materially altering the functions of the patient. During this continuance great deformity is generally produced. The alæ of the nose become swollen, the nostrils dilate, the lips are tumid, the external ears, especially the lobes, are enlarged and thickened and beset with tubercles, the skin of the cheek and forehead grows thick and tumid and forms large and prominent ruga, especially over the eyes; the hair of the eyebrows, beard, pubes, and axillæ falls off, the voice becomes hoarse and obscure, and the sensibility of the parts affected is obtuse or totally abolished, so that pinching or puncturing gives no uneasiness. This disfiguration of the countenance suggested the idea of the features of a satyr, or a wild beast; hence the disease was by some called satyriasis, or by others leoutiasis. As the malady proceeds the tubercles crack and ultimately ulcerate. Ulcerations also appear in the throat and nose, which sometimes destroy the palate and septum, the nose falls, and the breath is intolerably offensive, the fingers and toes gangrene and separate joint after joint." Aretæus and the ancients believed elephantiasis to be a universal cancer of the body, and spoke of it with terror. Aretæus prefixed to his description of the disease an account of the elephant in order, it is presumed, to point out the analogy between the formidable power of the beast and of the disease.

Guy de Chauliac, the celebrated surgeon of the fourteenth century, gives the following six symptoms as the most trustworthy of the malady: "Rotundity of the ears and eyes, thickening and tuberosity of the eyebrows, with falling off of the hair, dilatation and disfiguration of the nostrils externally, with stricture of them within, and fœtidity of the lips, fœtidity of the breath and of the whole person."

John of Gaddesden says no one should be adjudged a leper and separated from mankind until the figure and form of the face are actually changed.

Glanville, another English author who wrote in the fourteenth century, remarks that "leprous persons have redde pymples in the face out of whom oftene runne blood and matter; in such the noses swellen, the virtue of smelling faileth, and the breathe stynkyth right fowle, the voys is horse, the infectyd are unclene."

$A^{-}$good representation of leprosy in the Middle Ages is to be seen in a picture at Munich, by Holbein, painted at Augsburg early in the sixteenth century. St. Elizabeth is depicted as giving bread and wine to a group of lepers, including a man. whose bearded face is covered with large, round, reddish knobs ; an old woman whose arm is covered with brown blotches, the leg swathed in bandages through which matter oozes, the bare knee also marked with discoloured spots, and on the head a white cloth or plaster; and thirdly, a young man whose neck and face (especially round the somewhat hairless eyebrows) are spotted with brown patches of various sizes. It will thus be seen that almost from its very inception the symptoms of leprosy were not only well understood but clearly defined both by pen and brush. 
The Contagiousness of Leprosy.

That leprosy was believed to be contagious may be inferred from the efforts made by the ancients to seclude the diseased and prevent their communication with the healthy. Lepers were enforced by law and popular sentiment to wear a special costume, usually a long grey gown with hood drawn over the face, and to carry a wooden clapper to give warning of their approach, and to only indicate with a stick the articles they desired to buy in a market; they were forbidden to enter inns, churches, mills, or bakehouses, to touch healthy persons or eat with them, to wash in the streams, or to walk in narrow footpaths. For the segregation of lepers leper-houses existed in France in the seventh century, in Germany in the eighth, and in England in the eleventh century. Canonical laws were made in England preventing lepers from marrying. We have it on the authority of one of the most brilliant writers in connexion with English mediæval history-the Benedictine monk Mathew Paris-that there were 19,000 leper houses in Christendom in the thirteenth century, and that an order of knighthood dedicated to St. Lazarus was instituted, the members of which had the care of lepers and the control of leper houses. The number in France is independently estimated at 2000, while according to the late Sir James Simpson there were in England 95 religious hospitals for lepers, besides innumerable smaller pest houses, in addition to several in Treland and Scotland. It is interesting to note there were no new leper hospitals built in England after the fifteenth century, towárds the end of which time scarcely a trace of tuberculated leprosy could be found in any of the more civilised parts of Europe. The disease has, however, persisted in a few isolated spots, especially in the west coast of Norway, about Bergen, Iceland, and in some parts of Spain. In 1890 there were in Norway 1100 lepers; in 1906 there were only 500. According to Dr. George Pernet's latest statistics there are about 40 lepers at present in the United Kingdom. It was not until the researches of Danielssen and Boeick, of Norway, who in 1842 began the study of the disease in their own country and elsewhere under the name of Spedalskhed, together with the coöperation of Hebra in 1852 and Virchow in 1859, that a serious endeavour was made to differentiate leprosy from a whole series of very different cutaneous affections with which it had been for centuries confounded. The influence which bacteriology was beginning about this time to exercise on clinical medicine received an additional filip in the discovery of the lepra bacillus by Hansen in 1880. From this time onward the cause and communicability of leprosy became a scientific fact; the only missing link in Hansen's chain of evidence-and the link is still absent-is the inability to transmit with certainty, by inoculation or otherwise, the cultivated bacillus to animal or man. All attempts to transmit leprosy to man by inoculation have hitherto failed, with one exception, which is open to question. A Sandwich Island criminal named Keanu, apparently at the time free from leprosy, and whose sentence of death was commuted on the condition that he should submit to inoculation, was inoculated by Arning from a lepra nodule in 1884. Within six weeks he developed symptoms of leprosy. In about two years later he was a pronounced leper, and in six years from the date of inoculation he died from leprosy. The subject of the experiment was a native of a country in which leprosy was endemic, and members of his family had had leprosy. The short period of incubation and the previous com. munication with lepers discount the evidence of inoculation in this case.

\section{Obscurity of the Mode of Infection.}

It must be allowed that in our present knowledge of leprosy the mode of infection is obscure, whether by food, water, air, man or beast, by the broken or unbroken skin, are questions respecting all of which much diversity of opinion still exists, and whether the infecting germ enters the body as a spore or a bacillus for the present lacks confirmation. That infection does take place is no longer open to con. troversy, and that the infection comes from another leper is equally well established, for as leprosy is a germ disease it cannot originate de novo; it must come from a pre-existing germ whose habitat is probably man, because so far its presence has only been demonstrated in human tissues. Thus the general statement may be made that neither climate, race, soil, nor food can by any possibility originate leprosy, but that in countries where it is already endemic it may be perpetuated by any one or all of these.

The hereditary nature of leprosy, once so uni. versally accepted, has but few supporters to-day. Virchow and Kaposi were amongst the first to point out this fallacy by proving that the most the supporters of heredity could possibly claim would be an individual susceptibility. Manson disposes of the question of heredity in the following terse but forcible sentence: "Physiological peculiarities may be inherited but parasites never."

That leprosy is propagated by contagion and by contagion only is now almost universally accepted; the following case, in proof thereof, pre-eminently stands out. In 1872 Dr. (now Sir) Hawtrey Benson exhibited before the Medical Society of the Royal College of Physicians of Ireland ${ }^{1}$ a man who had contracted leprosy in the West Indies, where he had lived for 22 years. After remaining a certain time in the hospital he returned to his Irish home and died after about a year and a half During this latter period his brother slept in the same bed with him and wore his clothes. His brother, who had never left Ireland, except 46 years before, when he had passed some time in England, became a leper, and was shown, in 1877, to the same society. There had been no other cases of leprosy known in the family.

Probably the most historic case of individual infection is that of the Belgian priest, Father Damien, born in 1840 almost uncer the shadow of his much-loved and once famous Louvain University. With just a slight stretch of the imagination, we in our own time can see Father Damien, leaving the harbour of Honolulu, the capital of the Sandwich Islands, with his consignment of fifty lepers of all ages, creeds, and classes, en route for Molokai, one of the smallest islands of the Pacific which constitutes the Sandwich group. To this desolate spot the Hawaiian Government, in 1865, banished all the lepers, some of royal blood. Here they were doomed to live while life should last; here they were doomed to die. Father Damien gave himself to the lepers in 1873, and counted the cost, for he contracted leprosy in 1882 and died in 1899. There are forms of death from which human heroism has ever shrunkthere is a living death, slow, painful, and repulsive. 
It has fallen to my lot to have seen and examined a leprosy patient in the very last stages of this loathsome disease (the patient I now exhibit is by no means a good example). For those of you who have not had that experience permit me to give a description by an eye-witness: "A corner of the blanket was cautiously raised, a breathing object laid beneath, a face, a human face turned slowly towards us, a face on which scarcely a trace of humanity remained. The dark skin was puffed, a kind of débris, gummy and glistening, covered it, the muscles of the mouth had contracted and laid bare the grinning teeth, the thickened tongue lay like a fig between them, the eyelids curled tightly back exposing the inner surface, and the protruding eyeballs, now shapeless and broken, looked not unlike burst grapes.'

\section{The EFFEcts of BACTERIOLOGY UPON THE StUdy} OF LEPROSY.

I shall now consider briefly a few of the more important advances in the study of leprosy to which clinical medicine and dermatology (especially the latter) owe to bacteriology. I prefer to take up these advances in the order in which they were applied, in the diagnosis of this case, rather than attempt a classification founded on their respective importance.

\section{The Tuberculin Test for Leprosy.}

In 1891 Goldsmidt, among many others, observed that lepers reacted with a rise of temperature on injection with Alt-tuberculin. Jadassohn failed to produce any reaction with tuberculin in four cases experimented upon. In the case under review I failed to get any reaction with Alttuberculin injected subcutaneously or by Ton Pirquet's method.

\section{The Wassermann Test.}

The Wassermann test for leprosy stands thus, according to the conclusions of Howard Fox: $(a)$ A positive Wassermann reaction is frequently obtained in cases of leprosy giving no history or symptoms of syphilis; and (b) the reaction occurs chiefly in the tubercular and mixed forms, rarely, if ever, in the anæsthetic form. Professor E. J. McWeeney applied the Wassermann test in this case, which was very markedly positive.

The Experimental Transmission of Leprosy to Animals.

In 1912 Bayon injected four rats on two occasions in the testis with ground-up nodules from a case of leprosy. Two rats did not show any microscopic lesions even after four months. One rat, however, developed four weeks afterwards a nodule at the site of inoculation, which grew to the size of a small pea. On puncture it showed acid-fast germs and necrosed tissue, some of which, no doubt, represented the original cells injected. After five weeks the rat died, but no acid-fast micro-organisms were found in the organs. The disease, if transmitted, was localised. The whole of the nodule was then injected subcutaneously into two other young rats. Three months after inoculation one of the rats developed small shotty nodules under the skin. The other rat developed three months after the second injection a nodule in the left testis. This broke down and was found to contain acid-fast rods in great quantity. This rat was killed four months after inoculation. At the site of injection and in the corresponding inguinal glands numerous acid-fast rods were found. One of these small glands was inoculated into the testis of another rat, and on killing it six months afterwards no acid-fast microorganisms were found in the testis, but definite deposits were present in the inguinal glands, spleen, and liver.

In 1912-13-14, at Robben Island, Bayon made experiments on rabbits by means of the intraocular method. A single rabbit of the 30 inoculated has shown lesions in the iris and cornea.

Duval inoculated a series of animals-four rats, four white mice, and four Japanese dancing micewith material taken from an acute case of leprosy ( 0.5 c.c. emulsified in 1 c.c. normal saline solution). Some were injected intraperitoneally, others sub. cutaneously. The two white mice which received intraperitoneal injections died 14 days later. At the necropsy both showed general infection of the peritoneum with leprosy.

These are some of the successful attempts to transmit leprosy to animals by means of inoculation or injection of leprous tissue. Mr. T. T. O'Farrell, F.R.C.S., pathologist to the City of Dublin Hospital for Diseases of the Skin and Cancer, inoculated a mouse with leprous tissue from my patient on March 31st. The animal so far shows no macroscopic symptoms.

\section{Rat Leprosy.}

In 1903 Stephansky, of Odessa, discovered amongst the sewer rats of his city a disease nearly akin to leprosy, not only clinically, but histologically and bacteriologically. Its presence amongst the sewer rats of Berlin, Paris, and London has since been confirmed.

Dean, of London, succeeded in isolating a diphtheroid organism which showed filamentary forms and reacted specifically with the serum of lepers. Thus (a) serum of rats inoculated with rat leprosy (i.e., acid-fast bacilli) agglutinated the diphtheroid (normal rat serum had no agglutinating properties for this micro-organism) ; (b) serum from a case of human leprosy agglutinated the acid-fast microorganism from the rat (normal human serum had no agglutinating power); and (c) normal human serum and the serum from a tuberculous patient failed to agglutinate the diphtheroid, whereas the serum from a case of leprosy had distinct agglutinating properties.

The foregoing tests, in addition to the histological appearances and cultural behaviour of the micro-organism causing the disease in rats, suggest that rat leprosy is possibly related to human leprosy in a manner similar to that between bovine and human tuberculosis. Though rat leprosy seems spread over all the world, yet the 16,000 rats examined at Sandwich Islands and the 1378 at Cape Town gave negative results.

\section{Other Animals than Rats Affected.}

Rats are not the only animals affected by a disease akin to leprosy. Acid-fast micro-organisms which belong to the tubercle group cause disease in cattle, horses, and sheep. In cattle the disease is termed "enteritis hypertrophica bovis specifica." McFadyean, McGowan, and others have described Johnes's bacillus in the sheep, which differs from rat leprosy only in that the symptoms are confined to the digestire tract.

The ARtificial Cultrvation of Leprosy.

Sir Patrick Manson was the first to attempt the artificial cultivation of the micro-organism, and he was followed by Hansen and later by Neisser in 1881, with equal want of success. In 
1910 Kedrowsky published his experiments, which took ten years to complete. His first inoculations from the nodules of three lepers gave as a result two distinct bacteria, one a non-acid-fast filamentary, interlacing, branching organism, the other a slightly acid-resisting diphtheroid. He injected these bacteria strains singly into mice and rabbits under the dura, intravenously and intraperitoneally, and observed the animals in some cases for two years. He found that whatever micro-organism he had injected the result was the same in all cases- - iz., numerous acid-fast microorganisms of the tubercle bacillus type in the viscera, from which they could be regained in pure culture as acid-fast rods. The resulting lesions resembled in some cases the type of tuberculosis induced in rabbits by injections of human tuberculosis; in others the lesions closely resembled those occurring in visceral leprosy of human beings.

Kedrowsky's acid-fast culture of Hansen's bacillus is a moist creamy-white culture which resembles avian tuberculosis. It grows only at incubator temperature on special media, such as placental juice agar, glycerine agar, or any similar medium suitable for tubercle. Multiplication is generally apparent in ten days, but may take three weeks to reach the maximum. No growth takes place at room temperature or on gelatin. It is acid-fast, cannot be bleached by 20 per cent. nitric acid in one minute after staining for five minutes with warm carbol-fuchsin. It is alcohol-fast and will withstand absolute alcohol for ten minutes.

Bayon confirmed Kedrowsky's results in 1911 , and remarks that every experiment connected with leprosy should be repeated scores of times. He further points out that the crucial experiment to be carried out with any culture isolated from a leper is not only to get it to acquire the acid-fast properties and the morphology of the bacillus seen in tissues, but also to succeed in producing lesions analogous to those seen in lepers and in rats spontaneously infected with B. lepræ muris.

Bearing in mind the great difficulties encountered in transmitting leprosy to animals from the injec. tion or inoculation of nodules teeming with bacilli, many series of negative results must be faced. But negative results, even numerous, can never destroy a single positive observation.

\section{ACCOUNT OF a CASE OF Leprosy.}

The history of the case which I now present is as follows :-

In March, 1915, the patient was admitted to the City of Dublin Hospital for Diseases of the Skin and Cancer, and the disease was diagnosed for the first time by me. His father was a soldier and had served through the Indian Mutiny, having reached the rank of colour-sergeant in the Hampshire Regiment. $\mathrm{He}$ retired after 21 years' active service, and died at the age of 58. The subject of these notes is 38 years old. He was born in Belfast in 1877 and migrated to Birr as a child, where he lived until 1895, when he joined the army and served in the Leinster Regiment for 12 years-two at home and 10 abroad-retiring in 1906 . His foreign service in cluded the following stations: Malta, one year; Bermuda, two years; Halifax, one year; Jamaica, one year; and South Africa, five years. He served through most of the South African campaign, and was present at the relief of Ladysmith. He had always enjoyed excellent health. He developed synovitis of the right knee-joint, the result of a kick in the football field. and was invalided home for months in 1899. In Malta he had colic for three weeks in 1897, and had contracted gonorrhoea in Halifax in 1898. He definitely states that he has never had syphilis, and I have failed to detect any signs of it. He left the army in 1906, and worked as a farm labourer in the neighbourhood of Birr until 1911, when he dislocated his left elbow and remained for four months in Birr Hospital. In the autumn of 1913 a crop of boils appeared on the back of the neck. and his eres became red and somewhat swollen. He was again admitted to Birr Hospital, where he remained about five months, after which he was able to work, and did until August, 1914, when he sought to join the colours, but was rejected by the examining officer at Birr because of a skin rash. From Angust, 1914, he worked as a farm labourer until February, 1915. He was sent to Dublin in March, where he has since remained under my care. His mother died giving birth to her fifth child. Three sisters and one brother are alive and healthy. The

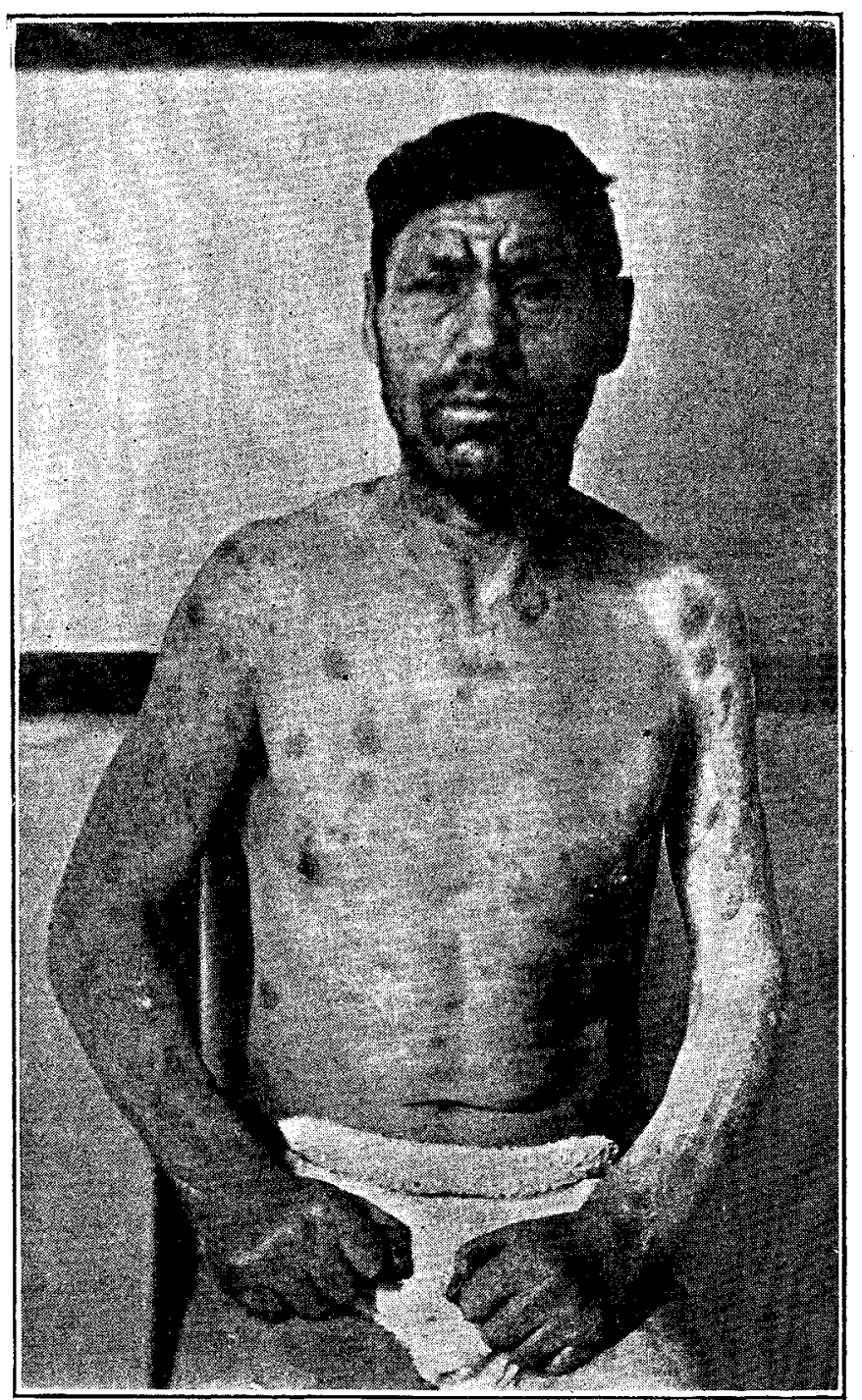

A case of leprosy.

brother is at present serving with the colours in France. The patient complainel of feeling weak on slight exertion with occasional shooting pains in the back and the shoulders. At times he had sensations of "hot and cold" all over the body. He thought the skin of the face, especially over the forehead, was becoming too tight and going to crack. His eyes were often bloodshot. Sleeping and appetite and digestion were good. The face was broader than normal; the skin was thickened, dark-brown and glistening, especially over the forehead, of which the furrows were very deep. The folds over the eyebrows were prominent and studded with tubercles, and over these the hairs were scanty, especially at the outer side. The nose was thick, broad, and flattened, the chin broad and unusually prominent, the beard very scanty, and the lips thick. There were infiltrations and tubercles on the neck, shoulders, and nates, both grouped and disseminated. On the extremities the infiltrations and tubercles tended to be symmetrical. The hands were swollen and cushion-like on the back, ash-grey in colour; the thenar and hypothenar muscles were flat and flabby; inguinal glands shotty ; reflexes normal; no anæsthesia; mucous membranes free. 


\section{CONCLUSION.}

In conclusion, I respectfully submit that the case which is the subject of this communication is not only instructive but interesting for the following reasons: 1. Because it possesses many of the clinical characteristics of tuberculated leprosy in the early stages, as insisted upon by both ancient and modern writers. 2. The case shows, as far as a single case can, that the Wassermann test for syphilis is not truly specific. 3. It shows, too, that the Wassermann test for leprosy is equally nonspecific. 4. The case also shows that the tuberculin test in the diagnosis of leprosy carries with it but little conviction. 5. The portion taken from a leprous nodule of this patient and stained by the Ziehl-Neelsen method shows many bacilli, a few of which may be seen within the cells, while the majority are scattered about the lymph spaces.

Unquestionably the study of leprosy, in its tout ensemble, shows marked advance. This advance to me appears overshadowed by the tragedy of events, which testify that after all these centuries of expectancy and perseverance we have not a single cure of confirmed leprosy to the credit of science. Those cases cured by the Holy of Holies, as recorded in Scripture, come under quite a different category, of course.

I have borrowed freely from the experience and works of many; more especially is this the case as regards Bayon, Sir Patrick Manson, and Castellani. I am also much indebted to my colleagues, Sir Thomas Myles, who confirmed my clinical diagnosis, and to Mr. T. T. O'Farrell, who prepared the slides shown, and also carried out the inoculations. My indebtedness is in an especial manner due to Professor E. J. McWeeney, who kindly applied the Wassermann test at his laboratory at University College, Dublin.

\section{ON PHANTOM ANEURYSMS.}

BY SAMUEL WEST, M.D. OxoN., F.R.C.P. LoND., CONSULTING PHYSICIAN, ST. BARTHOLOMEW'S HOSPITAL, LONDON, ETC.

THE functional affections of the arterial system fall into two groups according as they are characterised by dilatation or by contraction, and each of these may again be subdivided according as the change is widespread or local. In most of those in which there is dilatation there is also arterial throbbing, widespread or local, and this is the usual symptom which directs attention to the dilatation. The instance commonly cited of general arterial dilatation and throbbing is exophthalmic goitre, though it is very doubtful if it be correct to refer this to a primary vaso-motor disturbance, for according to present views its cause is toxic.

Clinically it is the local dilatations that are of most interest, because of the difficulties of diagnosis with which they may be attended. The best recognised form is that which is described as "abdominal pulsation" or "pulsating aorta." This was called by Morgagni "aneurysme bâtard," and by Paget "mimic aneurysm." In my student days it was by no means uncommon to meet with these cases in the wards, and they bad been for the most part sent into the hospital because of their having been diagnosed as abdominal aneurysm and treated as such without avail. Such cases are now much less seldom met with in the wards-not, I imagine, because they are $r \in$ ally raxer, for they were never very commou, but because the condition is now more generally recognised and treated on different lines.
Laennec gave an excellent clinical description of the pulsating aorta, to which little has been added since. It is generally stated that the dilatation of the abdominal aorta is general, and is in the longitudinal direction, and that there is no lateral distension, so that the fingers placed on each side of the vessel are not separated with each pulsation. This is not strictly accurate, though it is true that the pulsation is felt much more distinctly in the length of the vessel than transversely. At any rate, it is not local as in aneurysm. In the case in which owing to arterial disease there is general and not merely local dilatation, the tubular as distinguished from the saccular aneurysm, the other more important and characteristic difference comes in-viz., that in aneurysm the condition is permanent, and in the non-aneurysmal form it is transient or intermittent. Here I may quote Paget, who says in his well-known clinical lecture on this subject: "This mimicry is most frequent in the abdominal aorta, in which it has often been described as a nexrous abdominal pulsation, but, so far as I know, it is not described as occurring in the subclavian, innominate, and carotid arteries, though in them it is not very rare, and sometimes not easy of diagnosis."

In the St. Bartholomew's Hospital Reports for 1880 I described a series of such cases under the title of " Mimic or Phantom Aneurysms." Phantom aneurysm is, I think, the better name, for it suggests the clinical category to which they really belong-viz., that of phantom tumours. The case which first attracted my attention to this affection was thus described. It was that of a man who complained of indefinite aches and pains. On examining the chest I noticed under the outer half of the left clavicle an oval, pulsating tumour above which the veins were dilated, and in which a thrill was felt and a murmur audible. The tumour was of the size of a small hen's egg, though not quite so prominent as this might imply. The patient's chest was examined by two students before and after I examined it, both of whom reported nothing wrong, and on proceeding to demonstrate what I believed to be an axillary aneurysm I was surprised to find the tumour with the thrill and murmur gone. The patient was allowed to rest quietly for some minutes and was then again examined. All the physical signs returned-tumour, dilated veins, thrill, and murmur; but while under observation the tumour gradually subsided and the other physical signs decreased, until in two or three minutes all had disappeared. The experiment was repeated several times with equal success. The physical signs were, it was found, in no way affected by the position of the arms, although repeated movement of the arms quickly reproduced them; but so also did any movement, even walking with the arms hanging by the side. The signs were clearly those of temporary dilatation of the axillary artery, and this case might be described as one of mimic or phantom aneurysm.

In the paper above mentioned I described eight cases. Seven of the patients were males and, with the exception of one, all in the middle period of life. They all came to the hospital complaining of symptoms of debility or nervousness, and, in four of the cases, of discomfort in the subclavian region. Though two were muscular men, the others were not so, and some of them were decidedly weak and ill-developed. The swelling was unilateral in half the cases, and in the other half more marked on one side than on the other. A murmur occurred in all, and a thrill was noted in six. Dilated veins 